\title{
Activismo y contractivismo - arte y movilizaciones estudiantiles en el Chile reciente
}

Ignacio Szmulewicz $R$. $^{*}$

http://dx.doi.org/10.22409/poiesis.1829.145160

\begin{abstract}
RESUMEN: Desde mediados del 2011 los centros de las principales ciudades de Chile se han ido llenando de acciones, intervenciones, lienzos gigantes, objetos escultóricos efímeros y performance, espontáneas algunas, calculadas y meditadas otras, todas compartiendo un tema y un contenido: el estado polémico de la educación en el país. Aun cuando han perseguido un objetivo común, ciertas manifestaciones se diferenciaron de otras por estar impulsadas por una evidente voluntad de obra o proyecto artístico, por ser coordinadas y realizadas por colectivos de estudiantes de arte o bien por tener un grado de complejidad mayor que la simple y llana estética panfletaria. Mi intención en esta ponencia es analizar estas manifestaciones como parte de un incipiente escenario que hunde sus raíces y se vincula con mayor fuerza al arte público contemporáneo, particularmente a las líneas del activismo y el contra-monumento.

PALAVRAS-CLAVE: colectivos, arte público contemporáneo, activismo, contra-monumento

ABSTRACT: Since the middle of 2011 the centers of the main cities of Chile have been filled with actions, interventions, giant canvases, ephemeral sculptural objects and performance, some spontaneous, others calculated and meditated, all sharing a theme and content: the state controversial of education in the country. Even though they have pursued a common goal, certain manifestations were differentiated from others because they were driven by an obvious will to work or
\end{abstract}

\footnotetext{
* Ignacio Smulewicz es Historiador del arte, formado en la Universidad de Chile, Magíster en Arquitectura por la Pontificia Universidad Católica de Chile, que se ha especializado en las áreas de arte moderno y contemporáneo, arte público, chileno y latinoamericano. Ha publicado los libros Fuera del cubo blanco: lecturas sobre arte público contemporáneo (Metales Pesados, 2012), Arte, ciudad y esfera pública en Chile (Metales Pesados, 2015) y El acantilado de la libertad. Antología de crónicas valdivianas 1977-1992 (Kultrún, 2015), mientras que como crítico de arte ha colaborado para medios como Punto de Fuga, Artishock, Arte y Crítica y Caballo de Proa. Actualmente, escribe para la revista La Panera y es Coordinador del Centro de Documentación de las Artes Visuales del Centro Cultural Palacio La Moneda. E-mail: ignacioszmulewicz@gmail.com.
} 
artistic project, because they were coordinated and carried out by groups of art students or because they were more complex than simple and flat pamphlet aesthetics. My intention in this paper is to analyze these manifestations as part of an incipient scenario that has its roots and is linked more strongly to contemporary public art, particularly to the lines of activism and counter-monument.

KEYWORDS: collectives, contemporary public art, activism, counter-monument

Si todos vivimos inmersos en una "sociedad del espectáculo", ¿por qué no aprovechar algunos de sus recursos en una ampliación participativa de un arte problematizador, de discusión, incluso radical y subversivo?

-- Gerardo Mosquera

\section{La estridencia de la calle}

Desde mediados del 2011 los centros de las principales ciudades de Chile se han ido llenando de acciones, intervenciones, lienzos gigantes, objetos escultóricos efímeros y performance, espontáneas algunas, calculadas y meditadas otras, todas compartiendo un tema y un contenido: el estado polémico de la educación en el país.

Aun cuando han perseguido un objetivo común, ciertas manifestaciones se diferenciaron de otras por estar impulsadas por una evidente voluntad de obra o proyecto artístico, por ser coordinadas y realizadas por colectivos de estudiantes de arte o bien por tener un grado de complejidad mayor que la simple y llana estética panfletaria.

Dos grupos de ejemplos distintos puedo citar al respecto. El primer grupo lo constituyen diversas acciones performáticas en el espacio público realizadas entre mayo y julio del 2011 por la Asamblea de Estudiantes de Arte² (AEEA): "Predicadores de la revolución", el 28 de mayo (un 
grupo de artistas que se representaron como predicadores evangélicos gritando consignas al comienzo de una marcha estudiantil en la Plaza Italia); "El estridentazo", el 3 de junio y luego una segunda ocasión el 1 de julio (medio centenar de músicos dispuestos en la Plaza de la Ciudadanía que tomaron sus instrumentos sin ningún sentido de la armonía); “Los mendigos por la educación", el 7 de junio (un grupo reducido que en actitud penitente se dispuso en el Paseo Ahumada -reconocido lugar de prédicas, gritos y consignas- reclamando por el endeudamiento de los estudiantes) y "El yugo comunicacional", el 21 de julio (un desfile de personas que, con los rostros cubiertos, arrastraban desde sus cuellos televisores).

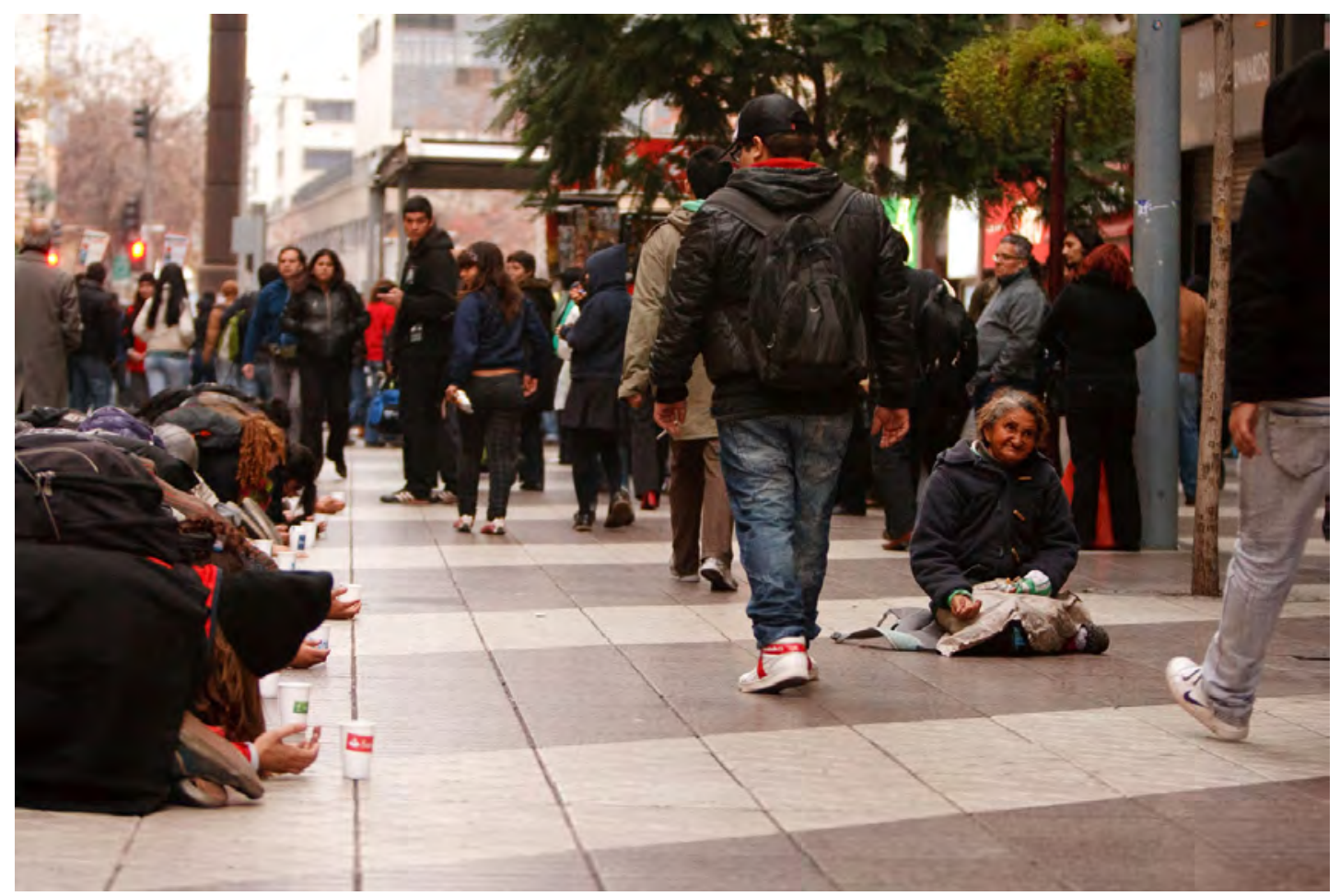

Asamblea de Estudiantes de Arte. Los mendigos por la educación. 7 de junio de 2011. Paseo Ahumada. 
El segundo grupo lo integran objetos escultóricos efímeros que han proliferado desde el 2011 de los talleres de la escuela de artes de la Universidad de Chile $^{3}$, algunos de gran escala, preparados expresamente para las masivas marchas y que, en algunos casos, estaban cercanos a los contra-monumentos. Estos representaron elementos simbólicos: un carro lanza-aguas de las fuerzas especiales (el Guanaco); una silla universitaria a gran escala; una recreación articulable de los martillos marchando en la famosa escena del video The Wall de Pink Floyd ${ }^{4}$, una alegoría de la justicia, entre muchos otros. Al igual que en el primer grupo, algunos de los objetos escultóricos construidos para las marchas eran quemados al finalizar el recorrido por la ciudad rescatando los conceptos de lo efímero y simbólico 5 .

Los medios de comunicación oficiales (escritos y digitales) vieron en estos ejemplos y en otros de corte más masivo, espectacular y pop ("Héroes y Villanos por la educación" el 18 de junio en la Plaza de Armas, "El Thriller por la educación" el 24 de junio frente al Palacio de la Moneda o "El baile de los que sobran", el 20 julio al comienzo del Paseo Bulnes) signos similares y vinculados con el carácter "artístico," "creativo" o bien "estético" que habían adquirido las últimas movilizaciones estudiantiles ${ }^{6}$.

Mi intención en esta ponencia es analizar estas manifestaciones como parte de un incipiente escenario que hunde sus raíces y se vincula con mayor fuerza al arte público contemporáneo, particularmente a las líneas del activismo y el contra-monumento.

En esta tradición de aproximaciones del arte público activista se encuentran los colectivos ASCO$^{7}$ (1972-1987), Group Material (1980-1992), Gran Fury (1988-1995), Critical Art Ensemble (desde 1987 en adelante) y, con una fuerza importantísima en Latinoamérica, Bijarí en Brasil (desde 1996 en adelante), Grupo de Arte Callejero en Argentina (desde 1997 en adelante), Colectivo Sociedad Civil en Perú (2000), entre muchos otros ${ }^{8}$.

Por tratarse de fenómenos que siguen ocurriendo en la actualidad y transformándose casi a la luz del día, resulta un contexto altamente significativo para analizar diferentes problemas: las categorías de obra y artista; la relación entre el arte y la sociedad; la tensión con los medios de prensa, entre otros. 


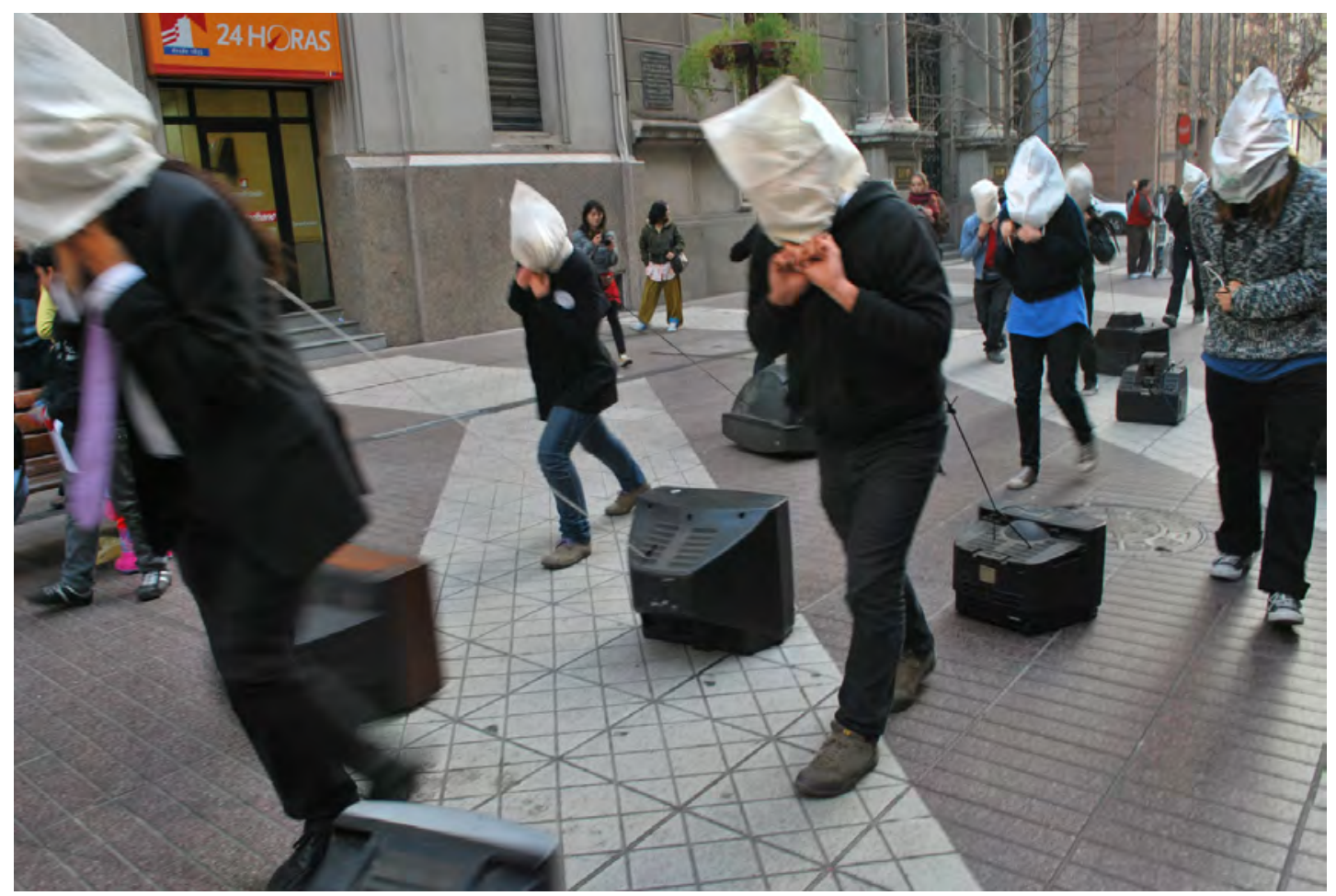

Asamblea de Estudiantes de Arte. El yugo comunicacional. 21 de julio de 2011. Paseo Ahumada.

\section{Por qué arte público}

La teoría e historia que ha ido emanando desde el arte público contemporáneo se cuenta entre las más ricas en el estudio de las relaciones entre arte y sociedad. Pensar así algunas de estas acciones realizadas desde las movilizaciones en defensa de la educación pública en Chile, principalmente las que emergieron desde artistas, con reflexión acerca de procesos de arte y con un marcado interés en cruzar el lenguaje artístico con los discursos de las manifestaciones, adquiere un potencial de comprensión mucho mayor. Sin embargo, estas relaciones no apuntan a cualquier concepto de arte público, sino que principalmente a visiones que enfatizan el arte público como una manifestación asociada a procesos y espacios conceptuales y críticos de (y con) la sociedad?. 
Si bien las acciones performáticas o los objetos escultóricos efímeros eran parte de una necesidad de comunicar un malestar ${ }^{10}$ con respecto a determinados problemas sociales vinculados a la educación, fueron utilizando esos espacios y momentos de crítica (la calle, la marcha, los edificios simbólicos, los entornos del centro de las ciudades) para experimentar formas de relación con la sociedad más complejas de lo que pueda asimilarse bajo nociones de la tradición del muralismo comprometido (la Brigada Ramona Parra) o bien el arte neovanguardista realizado durante la Dictadura11.

Del mismo modo, resulta imperioso discutir el constante mal uso del término intervención urbana para referirse a cualquier manifestación de corte artístico que se desarrolle en el espacio público ${ }^{12}$. El concepto de intervención urbana guarda relación con una voluntad de transgredir momentáneamente la lógica y cotidianidad de un lugar o entorno (y esto inspirado en las propuestas de Matta-Clark, Wodiczko, Christo \& Jeanne-Claude o bien en el caso de colectivos como 3nòs3 de Brasil o el C.A.D.A. en Chile). En palabras de Thomas Crow, refiriéndose a las obras de Gordon Matta-Clark: "su presencia se halla en total contradicción con la naturaleza del espacio que ocupa". (CROW, 2002, p. 141)

A diferencia de esto, las acciones performáticas y objetos escultóricos efímeros eran parte de un momento de interrupción pactada y programada con anterioridad (la marcha) para administrar y proteger todo tipo de diferencias o alteraciones sean artísticas o materiales. Por otro lado, a las acciones performáticas que se desmarcaron del tiempo de las marchas hay que incluirles una salvedad: se hicieron camuflándose con los lugares más emblemáticos del centro de las ciudades de Chile (en Santiago: Paseo Ahumada, la Plaza Italia, la Plaza de la Ciudadanía, entre otros).

Lo que resulta claro, a la luz de este incipiente escenario de arte público activista, es que se necesitan otros aportes teóricos e históricos. Para estas acciones encuentro en José Luis Brea, Félix Duque y William Mitchell, las definiciones más nítidas con respecto al concepto de arte público.

José Luis Brea establece que, pensando en colectivos artísticos con intención política-social como Critical Art Ensamble: "no llamamos arte público a cualquier mamotreto que se instala en un entorno urbano -digamos, absorbiendo la lógica del monumento- sino a aquellas 
prácticas artísticas y culturales que precisamente se dan por misión la producción de un dominio público [...] la producción de un espacio en el que a los ciudadanos les sea dado encontrarse, discutir y decidir a través de ese proceso de diálogo racionalmente conducido sobre los asuntos que les conciernen en común". (BREA, 2007, p. 14)

La interpretación que el filósofo español Félix Duque le otorga al arte público (aún cuando toma como ejemplos manifestaciones cercanas a los monumentos) aporta claves para entender la matriz de este problema: "no es un arte para el público, ni del público, sino un arte que toma como objeto de estudio al público mismo, a la vez que pretende elevar a ese público a sujeto consciente y responsable, no sólo de sus actos (último refugio ético del buen burgués), sino de los actos cometidos por otros contra otros [...] poniéndolos literalmente en ridículo con sus obras". (DUQUE, 2001, p. 108)

William Mitchell, en su ya clásica lectura del Vietnam Veterans Memorial (1982) de Maya Lin en tensión con la cinta Do the Right Thing (1989) de Spike Lee, abogaba por un "arte público crítico" que se "atreva a despertar a una esfera pública de resistencia, lucha y diálogo". (MITCHELL, 2009, p. 339)

Las tres acepciones apuntan a destacar el componente activo, crítico y emplazativo de parte de las prácticas del arte público, no tanto de formas y problemas de lenguaje específicos del campo del arte, sino que más bien de las posibilidades de movilización social por parte de experiencias inter-redes, participativas y críticas de los modos como se construye comunidad y espacio público.

\section{Activismo y contra-monumento}

He sostenido hacia el comienzo de la ponencia que las acciones performáticas y los objetos escultóricos efímeros, dado su intención, localización, problematización y contexto, han dado origen a una incipiente escena de arte público activista en Chile. Me parece plausible considerar que estas prácticas se nutren de la tradición del arte público, particularmente del activismo y de las lógicas del contra-monumento. 
Anna Maria Guasch, en su panorámica visión al arte producido después de la década de los sesenta del siglo XX, arroja la siguiente aseveración sobre el arte posmoderno activista: "de productor de objetos de arte, el artista pasó a 'manipulador' social de signos artísticos y, a su vez, el espectador dejó el papel pasivo contemplador estético o consumidor del espectáculo artístico, para convertirse en lector activo de mensajes. El arte se transformó en un signo social estrechamente ligado a otros signos en una estructura de sistemas productores de valor, poder y prestigio". (GUASCH, 2000, p. 476)

Si bien el extracto señala el potencial manipulador de la sociedad de parte de artistas o colectivos activistas el nacimiento del activismo en el arte de los ochenta del siglo XX, según la autora, se dio por una fuerte crítica hacia una cultura mercantilizada, impulsada por la década de la administración Reagan, a partir de una fuerte desplazamiento "fuera del cubo blanco".

De este modo, la conexión con el concepto de arte activista debe ir de la mano de un entendimiento del componente expansivo, inaprensible y complejo que conllevan las prácticas artísticas que se inmiscuyen en los terrenos ágiles y veloces de la política, la publicidad o los medios $^{13}$.

El teórico y curador cubano Gerardo Mosquera lo explicita de la siguiente manera: "ahora bien, la libertad y el ecumenismo metodológico de las prácticas artísticas contemporáneas, su flexibilidad y su acercamiento a otras actividades, disciplinas y a la 'vida real' pueden potenciarlas hacia una acción más vasta y colectiva, con mayores posibilidades sociales y políticas". (MOSQUERA, 2007, p. 83)

Por otro lado, el concepto de contra-monumento se origina desde prácticas de crítica del monumento y, además, a través de una resignificación de las formas de la conmemoración y el recuerdo. Esto en las propuestas de Krzysztof Wodiczko, Maya Lin, Haacke, hasta las más actuales de Fernando Sánchez Castillo o Ai WeiWei.

Se basaban en un cuestionamiento del monumento y de cómo se inscribía de manera violenta e impositiva la historia de los vencedores en el cuerpo de la ciudad. Por otro lado, los contra-monumentos de Wodiczko, Haacke o Sánchez Castillo apelan a deconstruir la historia de los monumentos: sea a través de la reposición de las historias ocultas (el Haacke de Und ihr habt doch gesiegt de 1988); o las parodias de lo monumental (el Sánchez Castillo de Spitting leaders de 2008) e incluso las contraposiciones discursivas (el Wodiczko del Homeless Projection de 1986) $)^{14}$. 


\section{Color local}

Una sintonía y afinidad mayor existe entre las prácticas que comenzaron en el horizonte común de los movimientos sociales en pro de la educación y los diferentes colectivos de Latinoamérica que han estado en busca de una activación política mayor a partir de elementos artísticos. Con la idea de generar un breve contexto comparativo citaré los ejemplos del Grupo de Arte Callejero (Argentina) y el colectivo Bijarí (Brasil).

El Grupo de Arte Callejero (GAC), integrado por Lorena Fabrizia Bossi, Vanessa Yanil Bossi, Fernanda Carrizo, Mariana Corral y Nadia Golder (han circulado por el grupo un número amplio de artistas y colaboradores), fue fundado a mediados de 1997, en el contexto de los reclamos de docentes hacia la promulgación de la Ley Federal de Educación. La primera aproximación al espacio público, en este escenario, vino de la mano de un "mural" colectivo, ritual y crítico que las entonces estudiantes de la Escuela Nacional de Bellas Artes Prilidiano Pueyrrredón impulsaron (Plaza Roberto Arlt el 20 de abril de 1997). Así fue descrito por sus integrantes: "esa primera salida fue experimental en todo sentido: no sólo por los materiales que usamos -poco frecuentes para un mural-, también por el carácter ritual que envolvía la atmósfera de la acción, oscilando entre un acto performático y una improvisación cargada de elementos simbólicos, a un hecho semiclandestino de toma del espacio". (CARRAS, 2009, p. 25) Y en relación al carácter ritual las integrantes del colectivo se refieren a la quema final del mural dejando sólo las cenizas y las quemaduras al muro (tal y como se han quemado en Chile los objetos escultóricos efímeros hechos por estudiantes de artes de la Universidad de Chile para las masivas marchas). A esa experiencia le seguirá la primera acción del conformado GAC: "Docentes ayunando", consistente en la distribución de diferentes murales críticos sobre los asuntos de la educación a lo largo de toda la ciudad de Buenos Aires.

Ese mismo año, dos acciones le siguieron a "Docentes ayunando": "Galería Callejera" y "Objetos en la Plaza Aramburu". En la primera, apareció una operación que sería una de las constantes del GAC, la intervención de los lugares destinados a la publicidad por parte de acciones de distorsión de signos y mensajes. Cuestión que, a partir del estrecho vínculo entre el GAC e H.I.J.O.S., se llamaría "escraches": "sacar a la luz lo que está oculto." Desde 1998, el escrache sería una de las prácticas más usadas por parte del GAC para denunciar en la vía pública el ocultamiento de las personas y los lugares donde se cometieron violaciones a los derechos humanos durante la última dictadura argentina (1976-1983) ${ }^{15}$. 
El colectivo Bijarí, integrado por arquitectos, urbanistas y artistas, se fundó en 1996 en São Paulo, con la finalidad de a través de procesos de arte cuestionar la manera como se construye la ciudad. Con una voluntad altamente crítica y emplazativa hacia la política y el urbanismo oficial, el colectivo ha logrado levantar debates sobre problemas de gentrificación, exclusión y marginalidad con mecanismos tan disímiles como la apropiación de espacios públicos, intervenciones efímeras de objetos críticos, trabajos comunitarios, etc.

Al igual que el GAC, Bijarí distorsiona los lugares y las estrategias de la publicidad para camuflarse e intervenir en los circuitos económicos, políticos o urbanísticos de la ciudad proponiendo acciones directas de cuestionamiento de la realidad ("Espacio público / Acción basura", São Paulo, 2008 o bien "Mula sem cabeza", São Paulo, 2006).

Una de las propuestas más completas se tituló "Están vendiendo nuestro espacio aéreo" (São Paulo, 2004 ${ }^{16}$ ) y consistió en una acción comunicativa y comunitaria de información y crítica sobre la especulación inmobiliaria en el sector de Largo da Batata que terminaba arrojando centenares de globos naranjos hacia el cielo por parte del colectivo y los habitantes del sector. Las manifestaciones artísticas realizadas desde el 2011 entroncan con esta tradición particular y localizada en un arte público activista en Latinoamérica. Sus elementos comparten formas y aproximaciones similares a temáticas tan disímiles como los problemas urbanos, las violaciones a los derechos humanos o bien la educación pública. Comparten una voluntad de crítica directa aunque no excluyen el desarrollo de experimentaciones visuales o procesuales ni tampoco de elementos simbólicos. Se basan en vínculos y pérdidas de límites entre esferas de acción, sean sociales, políticas, a través de agrupaciones comunitarias. Apelan más que a la discutida "eficiencia o impacto" del arte público a un intención de abrir espacios de contradicciones y debates, de diferencias y de encuentros, en su mayoría no oficiales (como fue sugerido por las definiciones de Brea, Duque o Mitchell) ${ }^{17}$.

\section{Por un activismo lúdico}

Las acciones performáticas y los objetos escultóricos efímeros guardan una serie de particularidades y especificidades que es necesario revisar para ir generando una descripción analítica más precisa de este incipiente escenario de arte público activista. 
Escultura de la justicia, Plaza Capitán Prat, Santiago de Chile, marcha por la educación, 11 de abril de 2013.

Tres características dan cuenta de este escenario. La primera de ellas, apunta a una retroalimentación crítica en la esfera pública con los medios de prensa y la cultura de masas. Se trató de experiencias que a nivel de producción artística estaban atentas y en un constante proceso de apropiaciones y desplazamientos de los signos y mensajes que emanaban del discurso oficial. Además, establecieron un vínculo crítico con la cultura de masas, guardando reparos con las manifestaciones que utilizaron como material e influjo la simple copia de formas y discursos de esa cultura pop (televisiva, digital y urbana) ${ }^{18}$. La principal operación fue relacionarse con elementos propios del lenguaje o la historia del arte (la escultura, la gráfica, la performance) en un entorno extraño y ajeno al del museo o la galería, generando una mezcla entre acción directa y explícita y profundidad de interpretación ${ }^{19}$. 


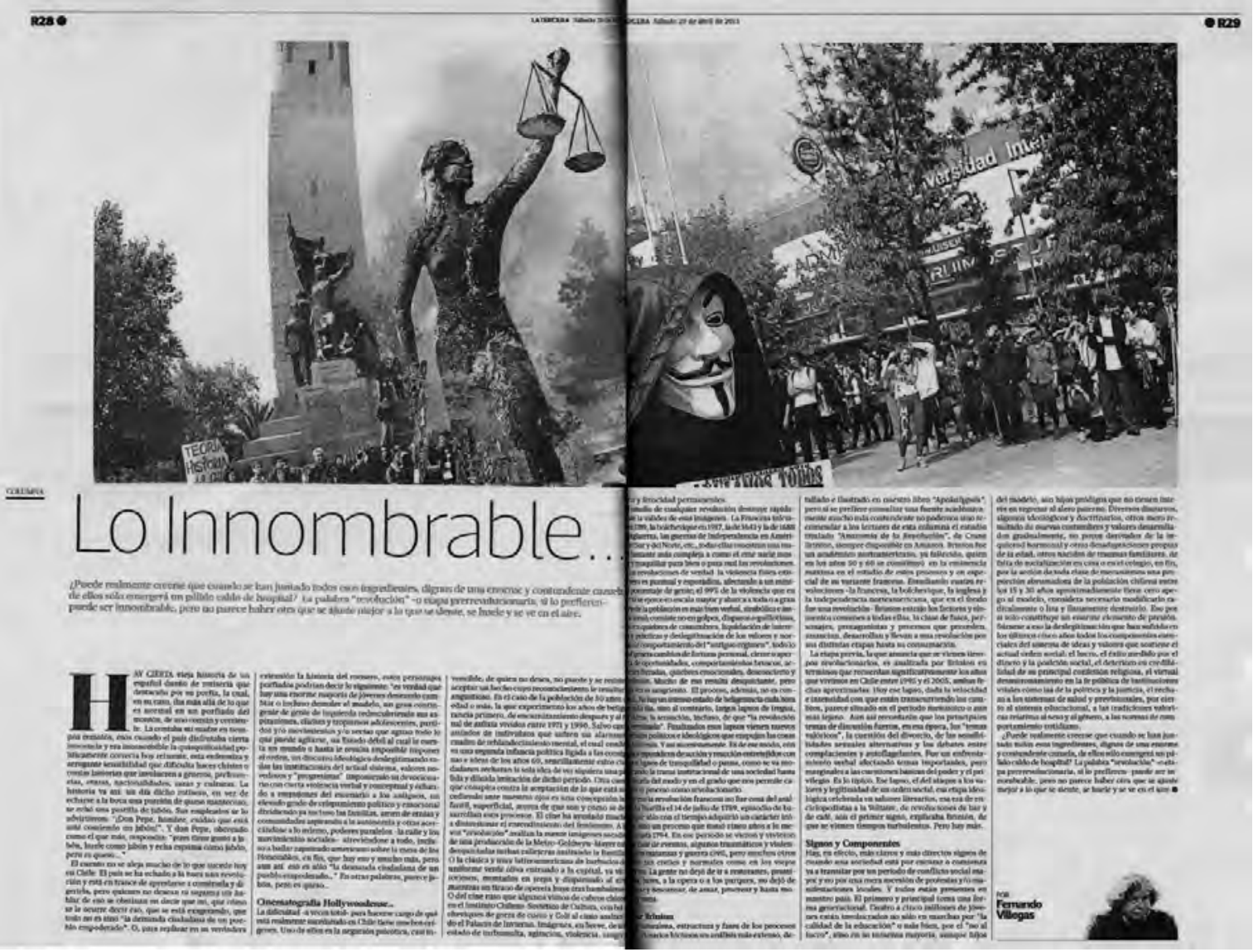

La Tercera, sábado 20 de abril de 2013.

(Fonte: Suplemento Tendencias, p. 28-29)

En segundo lugar, en su gran mayoría apelaron a un reposicionamiento del cuerpo en el espacio público. Y esto las diferencia, levemente, de las otras manifestaciones como el "Thriller por la educación" donde el componente de percepción digital o mediática es sumamente mayor ${ }^{20}$, y las acerca a las experiencias -dramáticas- que tienen que ver con el estímulo extremo del cuerpo en el espacio público ("Las 1800 horas por la educación", corrida colectiva alrededor del Palacio de la Moneda, propiciada por estudiantes de Teatro de la Universidad de Chile, entre el 13 de junio y el 27 de agosto del 2011).

Finalmente, la tercera característica estaría asociada a un tono y actitud lúdico, sarcástico e irónico en un contexto de fuertes críticas al sistema educacional (cuestión que lo alejaría de 
una porción importante del arte político latinoamericano que se ha caracterizado por la cercanía al drama o a la tragedia). Un humor crítico que lograría establecer una sintonía con la gran mayoría de personas que circula por la ciudad, contaminando la esfera pública con mensajes y discursos subversivos sin abstraerse de las mismas estrategias del espectáculo y la diversión ${ }^{21}$.

\section{Referencias}

CANDELA, Iria. Sombras de ciudad. Arte y transformación urbana en Nueva York, 1970-1990. Madrid: Alianza, 2007.

CARRAS, Rafaela. Pensamientos, prácticas y acciones del GAC. Buenos Aires: Tinta Limón, 2009.

CROW, Thomas. El arte moderno en la cultura de lo cotidiano. Madrid: Alianza, 2002.

DUQUE, Felix. Arte público y espacio político. Madrid: Alianza, 2001.

FINKELPEARL, Tom (ed.). Dialogues in Public Art. Cambridge, Mass.: The MIT Press, 2001.

FLORES, Mariairis; QUEZADA, Lucy. La dimensión artística de la manifestación: marchando desde la Facultad de Artes de la Universidad de Chile. En: W.AA. En marcha. Ensayos sobre arte, violencia y cuerpo en la manifestación social. Santiago: Adrede Editora, 2013.

GUASCH, Anna Maria. El arte último del siglo XX: del posminimalismo a lo multicultural. Madrid: Akal, 2000.

JACOB, Mary Jane. Extramuros. En: GUASCH, Anna Maria. Los manifiestos del arte posmoderno: textos de exposiciones, $1980-1995$ Madrid: Akal, 2000.

LONGONI, Ana; BRUZZONNE, Gustavo (comps). El siluetazo. Buenos Aires: Adriana Hidalgo Editora, 2008.

MITCHELL, W.T.J. Teoría de la imagen. Madrid: Akal, 2009.

MOSQUERA, Gerardo. Arte y política: contradicciones, disyuntivas y posibilidades. Revista Brumaria 8, Madrid, primavera del 2007.

SZMULEWICZ, Ignacio. Fuera del cubo blanco. Lecturas sobre arte público contemporáneo. Santiago: Metales Pesados 2012a.

SZMULEWICZ, Ignacio. Arte y movilizaciones estudiantiles. Conversación con Cristián Inostroza. Revista arteycritica.org, Santiago, n. 3, diciembre de 2012b.

VIDAL, Sebastián. Corriendo riesgos: arte, calle y coyuntura política. Revista arteycritica.org, Santiago, n. 1, julio de 2012.

W.AA. Bijarí. Bookart, formato digital, 2008.

W.AA. El arte de la historia. Fernando Sánchez Castillo. Ediciones del Departamento de Artes Visuales, Universidad de Chile, Santiago, 2011.

ZÚÑIGA, Rodrigo. La extensión fotográfica. Ensayos sobre el triunfo de lo fotográfico. Santiago: Metales Pesados, 2013.

\section{Notas}

1 Este texto fue publicado en el libro Pasados presentes. Debates por las memorias en el arte público en Latinoamérica. Cali: Universidad del Valle - GEAP Latinoamérica, 2015, editado por Teresa Espantoso R., Carmen C. Muñoz, Carlos M. Recio y Carolina Vanegas C. a propósito del IV Seminario Internacional sobre Arte Público en Latinoamérica.

2 Denominación de diversos estudiantes de escuelas de arte del país que se asociaron con la finalidad de recuperar una vocación política por parte de las expresiones artísticas pero a su vez criticar el modo como eran asumidas, estas mismas, por la política. Para ver más detalles sobre esta agrupación revisar la entrevista realizada por el autor de esta ponencia a Cristián Inostroza (SZMULEWICZ, 2012b). 
3 Flores y Quezada señalan lo siguiente: "la marcha el sitio preciso para su exhibición y la Universidad el lugar de su creación". (QUEZADA; FLORES, 2013)

4 Curiosamente, Roger Waters realizó dos multitudinarios conciertos del álbum The Wall el 2 y 3 de marzo de 2012 . En todas las versiones llevadas a cabo a conciertos de la ópera rock The Wall, los elementos tridimensionales articulables han sido importantísimos, siendo la más conocida la megalómana versión de 1990 en el Berlín post-muro.

5 La quema de objetos tridimensionales, sean carros alegóricos o esculturas, es de larga data, siendo el referente de las fallas de Valencia el más evidente aunque en el caso local sería más certero referirse a la fiesta de la Quema del Judas en Valparaíso que se realiza el último día de semana santa.

6 El diario La Tercera, el miércoles 29 de junio del 2011, escribió lo siguiente en un artículo acerca de la acción titulada "Suicidio en masa por la educación" (Valparaíso, martes 28 de junio, Plaza de Armas): "Sangre, fantasmas y zombis se observaron en estas intervenciones urbanas que exigen mejorar la calidad de la educación".

7 Una primera exposición retrospectiva del grupo se pudo ver en el MUAC de la Universidad Nacional Autónoma de México entre el 21 de marzo y el 28 de julio de 2013. La muestra se tituló Asco: elite de lo oscuro.

8 No es azaroso este cruce con colectivos ya que: "los estudiantes de artes visuales no emergen como sujetos ni como autores que intentan visibilizarse, sino a través de la institución académica de la que son parte (se marcha con el lienzo de la Facultad), vuelven transparente el mensaje disolviéndose como individuos a partir del anonimato de la obra. La importancia del sujeto es ahora la de la multitud, como aquella colectividad que desea una sociedad más justa". (FLORES; QUEZADA, 2013)

9 En este sentido, estas visiones son más amplias -pero no excluyentes- de aquellas que consideran al arte público como una extensión de los desarrollos del monumento y la escultura (Javier Maderuelo o María Sobrino), y, a su vez, no se enfocan sólo en la intención de transformar el espacio público de manera física o tangible (cosa apreciable por ejemplo en la trayectoria de Acconci Studio). Por último, esta mirada del arte público se conecta con una fuerte tradición desde la experimentación del arte contemporáneo y posmoderno del siglo XX, no así las visiones más asociadas al monumento conmemorativo del siglo XIX.

10 Término que se ha vuelto clave en el debate intelectual de los últimos cinco a diez años y que, desde los movimientos sociales del 2011 (educacionales, ambientales, étnicos, sexuales), se ha inscrito en el debate de la opinión pública.

11 Si bien es posible encontrar conexiones e interrelaciones, resulta radicalmente diferente por diversas razones que no serán discutidas en esta ponencia. Para una discusión acerca del tema ver el ensayo de Sebastián Vidal citado en la bibliografía. Flores y Quezada coinciden en este punto: "las obras anteriormente descritas tensionan el panorama que configura el mito del arte latinoamericano como ilustrativo y comprometido a modo de panfleto con la política y, en modo particular tensionan también el relato unívoco de un arte conceptual y críptico que se relaciona con la política en los límites de la censura dictatorial." (FLORES; QUEZADA, 2013)

12 Quizás el ejemplo más paradigmático de este excesivo abuso del término "intervención urbana" haya sido el I Festival Hecho en casa llevado a cabo en Santiago entre el 16 y el 25 de noviembre del 2012 que incluyó las más diversas expresiones visuales en la ciudad (en el territorio turístico). Algunos de los participantes fueron: Elliot Tupac, Brigada Ramona Parra, Sebastián Errázuriz, Grupo Grifo, Colectivo Casagrande, Pablo Curutchet, Estanpintando, Macay, Andrea Wolf, Payo, entre otros. Un simple examen del evento puede arrojar luces acerca de la concepción de intervención urbana que fue manejada por organizadores y artistas. Concepto que excluía los problemas esenciales del arte público contemporáneo: la relevancia de la investigación en el lugar; las acciones vinculantes o de participación con la comunidad o bien la crítica hacia las condiciones urbanas (marginación, exclusión o segregación). El perfecto anverso 
de este evento sería el proyecto de Nelson Brissac Arte e Cidade realizado en Sao Paulo desde 1994 o bien Valparaíso Intervenciones (accidentado por el terremoto del 28 de febrero del 2010, día original del lanzamiento del evento). Los participantes de este último fueron: Ricardo Basbaum, Colectivo Democracia, Guisela Munita, Esther Ferrer, entre muchos otros.

13 Bien lo han observado Flores y Quezada, al indicar tres de las principales características de esta incipiente escena de arte público activista. Estas serían la "intencionalidad", la "contingencia" y la "impronta comunicativa". (FLORES; QUEZADA, 2013)

14 Para analizar de manera más específica la línea de los contra-monumentos ver Iria Candela (2007, p. 145-164).

15 El GAC, además, ha llevado a cabo acciones de carácter performático, comunitario, a través de medios como la cartografía, la señalética, la intervención gráfica en un amplio registro de lugares, casi todos de alta significación histórica para el problema: las violaciones a los derechos humanos. La reciente publicación de Pensamientos, prácticas y acciones del GAC (Carras, 2009) es un aporte imprescindible para el estudio y valoración del arte público de corte activista desarrollado en Latinoamérica.

16 El proyecto fue parte del evento Zona de Acción, donde se invitó a otros colectivos activistas de Latinoamérica a intervenir en diferentes zonas de la ciudad de São Paulo. Entre los participantes se encontraban también el GAC, Contra filé, Cobaia, A revolução não será televisionada.

17 Otro aspecto de ese debate es el sugerido por Gerardo Mosquera: "la documentación es con frecuencia el superobjetivo presente desde el momento mismo de la concepción del proyecto, y la obra sólo el proceso que conduce a ella. Demasiadas veces pasan a segundo plano las implicaciones y efectividad social de estas obras". (2007, p. 83)

18 Y este punto serviría para matizar la observación de Gerardo Mosquera: "considero muy conveniente algunas aperturas del arte actual hacia recursos de la cultura de masas, el humor y el espectáculo, cuando éstas conllevan un filo crítico y la construcción de sentido". (MOSQUERA, 2007, p. 83)

19 Otro aporte desde Mosquera: “Una parte considerable del arte contemporáneo se vincula con otras actividades, a veces de acción social, o constituye un proceso diversificado donde se entra y sale de la esfera artística en distintos momentos y espacios, para entrar y salir de otros. Con frecuencia el arte abandona el cubo blanco y el cubo negro y se desenvuelve en la calle o en otros contextos no auráticos". (MOSQUERA, 2007, p. 81)

20 Esto ha sido analizado en el último libro de Rodrigo Zúñiga: "algunas de las intervenciones performáticas más recordadas de esta movilización fueron efectivamente planificadas en función de su circulación transmedial” (Zúñiga, 2013: 69).

21 Por citar otro ejemplo de esto, en una de las marchas del 2011, los estudiantes de arte elaboraron un objeto escultórico efímero que representó un carro de guerra romano, con el escudo chileno intervenido con los rostros del entonces Ministro de Educación Joaquín Lavín y el Ministro del Interior, Rodrigo Hinzpeter. Dirigiendo el carro, una gran representación del busto del presidente Sebastián Piñera. 